\title{
Impact of emulated inertia from wind power on under-frequency protection schemes of future power systems
}

\author{
Francisco Manuel GONZALEZ-LONGATT ${ }^{1}$
}

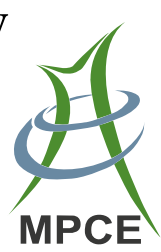

\begin{abstract}
Future power systems face several challenges. One of them is the use of high power converters that decouple new energy sources from the AC power grid. This situation decreases the total system inertia affecting its ability to overcome system frequency disturbances. The wind power industry has created several controllers to enable inertial response on wind turbines generators: artificial, emulated, simulated, or synthetic inertial. This paper deals with the issues related to the emulated inertia of wind turbines based on full-converters and their effect on the under-frequency protection schemes during the recovery period after system frequency disturbances happen. The main contribution of this paper is to demonstrate the recovery period of under-frequency transients in future power systems which integrate wind turbines with emulated inertia capability does not completely avoid the worse scenarios in terms of under-frequency load shedding. The extra power delivered from a wind turbine during frequency disturbances can substantially reduce the rate of frequency change. Thus it provides time for the active governors to respond.
\end{abstract}

Keywords Frequency controller, Frequency stability, Power system, Protection scheme, Wind turbine generator

CrossCheck date: 11 February 2015

Received: 2 February 2014/Accepted: 7 February 2015/Published online: 12 August 2015

(C) The Author(s) 2015. This article is published with open access at Springerlink.com

$\bowtie$ Francisco Manuel GONZALEZ-LONGATT

fglongatt@ fglongatt.org

1 Loughborough University, Loughborough LE652JG, UK

\section{Introduction}

Future power systems face several challenges [1]: (1) massive penetration levels of renewable energy coming from highly variable generators connected to power grid over power converters, (2) energy storage technologies with very different time constants, some of which use power converters as an interface to the power grid, (3) massive transmission network facilitating the integration of largescale renewable energy sources and the transportation of electricity based on underwater multi-terminal high voltage direct current (MTDC) transmission. These components have an element in common: high power converters that decouple the new energy sources from the pre-existent power grids [1-3].

During system frequency disturbances, the power balance between the generation and the demand is lost, and the system frequency will change at a rate initially determined by the total system inertia $H_{T}$ and the size of the power imbalance $\Delta P$. Future power systems will increase the installed power capacity but the effective system inertial will be the same, and then the system frequency response will stay the same nowadays. This is because the new generation units based on power converters provide a decoupling effect between the real inertia and the AC grid. The result is deeper frequency excursions during system frequency disturbances [1]. Based on a decreased inertial response, a considerable reduction in the ability to overcome system frequency disturbances is expected. The inertial response of the future power system might be negatively affected with devastating consequences for system security and reliability.

The inertial response of wind turbine generators (WTGs) has been an important topic. The original concept is initially presented in [4] and the controllers have been 
developed [4-7]. The theory behind those controllers has been developed in $[4,5,8]$. I. Erlich et al. [6, 7] used the initial response as primary frequency controller to support system frequency, identify some issues related to the way the kinetic energy is released from the wind turbine (WT) and two approaches are presented to cope with extreme changes at the WT rotational speeds: over-speeding and under-speeding. Few other papers have evaluated the impact on the inertial response provided by the WTGs on the performance of control schemes in future energy systems. Some of them provide general ideas about possible impacts on power systems and transient under-frequency response [3, 9, 10]. Even, some control strategies have been proposed to mitigate the impact of reduced inertia [11-15]. The interest of power utilities on the use of frequency support provided by this controller has been studied around the world in several reports such as National Grid plc [16] in Great Britain. However, there is not a universal agreement about the use of inertial response as auxiliary service to provide frequency support during system frequency disturbances. Furthermore, it lacks of knowledge about the impact of inertial response of wind turbines on deterministic under-frequency protection schemes in future power systems.

This paper presents the impact of emulated inertia controllers used in wind turbines based on full-converters on the under-frequency protection schemes during the recovery period after system frequency disturbances. The paper is organized as follows. Section 2 describes the frequency response on power systems after system frequency disturbances. Section 3 presents the concept of emulated inertia and show two approaches used on WTGs controller to create inertial responses. Section 4 addresses the aspects related to under-frequency protection schemes on power system and some potential challenges for future power systems. Section 5 shows the simulation results that define the impact of the emulated inertia on the under-frequency protection schemes over a test system. Finally, the advantages of the novel controller are discussed in Section 5.

\section{Frequency stability}

The frequency of power system depends on the balance between the generation and the demand. During normal operation of power system, the frequency is regulated within strict limits by adjusting the electrical supply to meet the demand. Responsibility of frequency control is managed in Great Britain by National Grid plc, thought the procurement and dispatch of frequency response services and the frequency is maintained at $50 \mathrm{~Hz} \pm 0.20 \mathrm{~Hz}$ under normal conditions $[16,17]$. If the balance between the generation and the demand is not reached, the system frequency will change at a rate which is dependent upon the initial power mismatch and the total system inertia.

Large frequency disturbances, particularly trips of large generation power plants, cause between the unbalance generation and demand that must be corrected by frequency control loops. These controllers are provided in order to improve the system frequency response (SFR). The frequency controllers cover multiple time-frames [1] (see Fig. 1): (1) inertial response is also known as fast primary response, (2) governor response is also known as slow primary response, and (3) automatic generation control (AGC) response. These controllers can define the dynamic changes associated to SFR.

Continuous services are provided by the generation units during normal conditions where frequency controllers act to compensate small frequency deviations $[18,19]$. During system frequency disturbance, the (1) inertial response dominates the initial frequency changes then the combination of system inertia and (2) governor response dictates the extreme value of frequency (maximum or minimum). Later, the governor response dominates the frequency mismatch between the system quasi-steady-state frequency and statutory value until (3) AGC takes over. Inertial and governor response represents the primary frequency response and it is an occasional service provided by the generation units [1]. AGC response is additional and slower compared with previous two controllers. The AGC controller includes the tertiary control which objective function depends on the organizational structure of the given power system and the role that power plant plays in the structure [1]. Primary response is provided locally at device level, secondary response is mainly area-wide inside an administrative area, and tertiary response is a global concept for interconnected systems and it is related with the services provided by the reserve.

SFR provided by WTGs is different to traditional generation systems. Modern variable-speed WTGs contribute

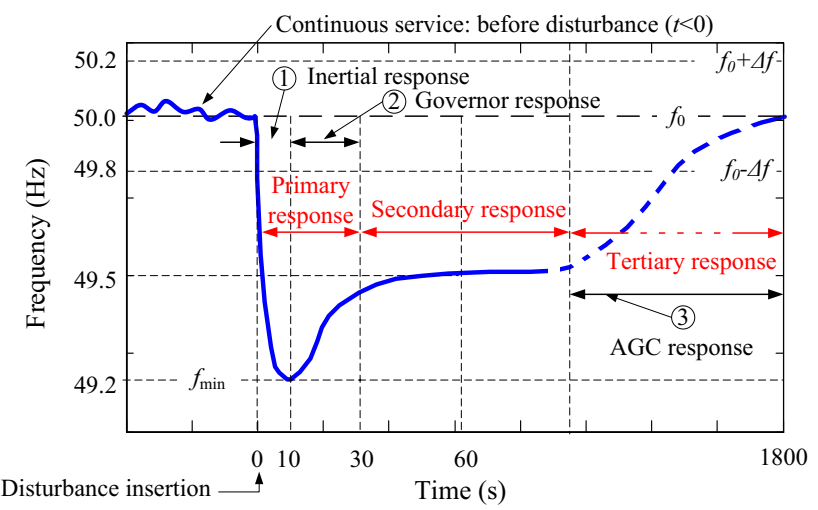

Fig. 1 Typical SFR based on system frequency disturbance including numerical references to GB frequency control system 
Table 1 Typical data for 3 MW WTG

\begin{tabular}{llrr}
\hline Drive train concept & Generator type & $\begin{array}{l}\text { Rated speed } \\
(\mathrm{r} / \mathrm{min})\end{array}$ & $\begin{array}{l}\text { Generator rotor } \\
\text { inertia }\left(\mathrm{kg} / \mathrm{m}^{2}\right)\end{array}$ \\
\hline Double fed 3-stage gear & Wound rotor, asynchronous, 6-pole & 1200 & 250 \\
Low speed full converter (LSFC) direct drive & Permanent magnet, multi pole & 14 & 40500 \\
Medium speed full converter (MSFC) 2-stage gear & Permanent magnet, 14-pole & 400 & 510 \\
High speed full converter (HSFC) 3-stage gear & Permanent magnet, 6-pole & 1600 & 115 \\
\hline
\end{tabular}

to neither system inertial nor governor response without incurring significant operational cost penalties.

\section{Frequency response of wind power}

The total system inertia of a traditional power system comprises of the combined inertia of the spinning generation and load connected to the power system. The contribution to the system inertia from a single load or generator depends on changes in the system frequency and causes the change in its rotational speed hence, a change of its kinetic energy. The power associated with the change in kinetic energy is fed or taken from the power system and is known as the inertial response. During a system frequency event the total system inertia response of all electrical machines connected to the system is the main factor that determines the initial rate of frequency change (ROCOF) [3].

Modern WTGs use power electronics converters to enable variable speed operation in order to capture wind energy over a wide range of speeds. However, these converters isolate the rotational speed from the system frequency, thus WTGs based on back-to-back AC/DC/AC converters offer no natural response to system frequency $[8,17]$. Some manufacturers have started to integrate controllers on modern WTGs in order to provide inertial response (governor response on some cases) for large short-duration frequency deviations.

The WT industry has created several names for this control system that enable inertial responses on WTGs: artificial, emulated, simulated, or synthetic inertial. Examples of synthetic inertia controller commercially available for WTGs are: General Electric WindINERTIA ${ }^{\mathrm{TM}}[9,20]$ and ENERCON ${ }^{\circledR}$ Inertia Emulation [9].

The objective of the emulated inertia controller is extracting the stored inertial energy from the moving parts on WTGs. The idea is to produce the incremental energy similar to that provided by a synchronous generator with real inertia. This is a local and automatic controller at WT level which has a response in the same time-frame as primary controllers $(<30.0 \mathrm{~s})$. Emulated inertia controllers are based on two different approaches: (1) releasing hidden inertia, (2) reserve capacity in pitch. This paper is interested in the first one.
Releasing the hidden inertia concept allows a controller to take the kinetic energy from a WT rotating mass. Significant energy is stored in a WTG, and electrical generator operating at high speed has a large amount kinetic energy stored in rotor of generator, but majority of the kinetic energy are in rotor bales. A WT using permanent magnet synchronous generator (PMSG) on a direct-drive concept has less kinetic energy stored due to the lower rotational speed. Table 1 shows typical values of 3.0 MW modern variable-speed WTG.

During system frequency disturbances, the frequency response of a synchronous generator is based on the generator-demand dynamic relationship between the load generation imbalance $\Delta p$ and the frequency $f$. It can be expressed using the frequency version of the classical swing equation:

$\frac{2 H}{f_{0}} \frac{\mathrm{d} f}{\mathrm{~d} t}=p_{m}-p_{e}=\Delta p$

where $p_{m}$ is the mechanical power of prime mover in p.u., $p_{e}$ is the electrical power in p.u., $\Delta p$ is the load generation imbalance in p.u., $H$ is the inertia constant of the generator, $H$ is given in seconds to be a measure of the time that a rotating generator can provide rated power without any input power from the turbine; $f$ is the frequency; $f_{0}$ is its rated value, and $\mathrm{d} f / \mathrm{d} t$ is ROCOF. That is a simplified version of the swing equation, considering the damping effect to be small during the event.

This inertial controller allows the WTGs to emulate the frequency response similar to the inertial response provided by synchronous generator by implementing a hidden inertia controller.

The idea behind the hidden inertia controller is produced in a converter based WTG frequency response that is comparable to the inertia of conventional generators using the appropriate signal, as consequence, the controller uses an approach based on the frequency version of the classical swing in (1).

Releasing the hidden inertia control loop increases electric power output of the WTGs during the initial stages of a significant downward frequency event. This controller is a simple control loop added in the power converter controller, which creates an active power control signal following a version of the swing equation: 
$\Delta P_{\text {Heтu }}=2 H_{\text {emu }} f_{\text {sys }} \frac{\mathrm{d} f_{\text {sys }}}{\mathrm{d} t}$

where $H_{e m u}$ is the emulated inertia and $f_{s y s}$ is the system frequency. It is an additional control loop injecting a new reference signal $\Delta P_{\text {Нети }}$ into reference signal $P_{\text {ref }}$ used by back-to-back converter of the WT. The emulated inertia is included in the closed loop controllers as the gain of a proportional transfer function, which can virtually have any value. However, the hidden inertia is based on releasing the kinetic energy from the WT rotating mass. Therefore, $H_{\text {emu }}$ must be related to the real inertia of the WT rotating components. A discussion about the optimal value of $H_{\text {emu }}$ is beyond the scope of this paper. However, this paper considers $H_{\text {emu }}$ is below the total WT inertia $H_{W T}$ and allows a longer kinetic energy contribution compared with higher $H_{\text {emu }}$.

The WT can quickly store and release a large amount of kinetic energy in the rotating masses, due to a large amount of inertia and wide rotational speed. However, the discharging of energy to the grid is only available for a short period $(<30.0 \mathrm{~s})$ and the recovery of WT power is supplied by the grid (unless the wind speed increases favorably).

Slowing the wind turbine reduces the aerodynamic lift and the security limitations must be considered to avoid a stall. Inertial power must respect WTG component rating like mechanical loading as well as converter and generator electrical rating [6]. For large under-frequency events, the inertial control feature temporarily increases the power output of the wind turbine by $5 \%$ to $10 \%$ of its rated power in several seconds. Some WTGs are able to contribute to the grid frequency response by adopting power feed-in in terms of the actual grid frequency, using an approach called the Fast Power Reserve Emulation. The controller enables the variable WTGs to increase the power output by $4 \%-10 \%$ of rated power in $10.0 \mathrm{~s} \mathrm{[9]}$.

\section{Protection scheme}

When severe system frequency disturbances occur, for example loss of a station (all generating units), loss of a major load centre, or loss of AC or DC interconnection, emergency control measures may be required to maintain frequency stability. These control measures include: generator tripping, fast generation reduction, HVDC power transfer control, load shedding, controlled opening of interconnection to neighboring systems to prevent spreading of frequency problems and controlled islanding of local system into separate areas with matching generation and load. Under-frequency load shedding (UFLS) is the most widely used protection against frequency collapse. Typically, the load is shed based on local frequency measurement in several steps by $5 \%-20 \%$ of the total feeder load. Automatic load shedding is implemented using under-frequency relays. The typical threshold values are $48-48.5 \mathrm{~Hz}$ in $50 \mathrm{~Hz}$ power systems.

The main drawback of these schemes is their delayed response since they must wait for the frequency to decline before taking action. A great proportion of inertia is expected to be decoupled to the system frequency in future power systems. As consequence, a larger frequency drop is expected in future networks, and deterministic frequency protection/control schemes must be re-thought. The synthetic inertial response from wind turbines can increase system security and aid large-scale systems to overcome system frequency disturbances. However, control interactions can create disastrous situations.

\section{Simulations and results}

This section presents the simulations and results over the test system which is the representative of future network. DIgSILENT $^{\circledR}$ PowerFactory $^{\text {TM }}$ [21] is used for time-domain simulations and DIgSILENT Simulation Language (DSL) is used for dynamic modelling. All simulations are performed using a personal computer based on Intel ${ }^{\circledR}$, Core $^{\mathrm{TM}}$ i7 CPU $2.0 \mathrm{GHz}, 8 \mathrm{~GB}$ RAM with Windows 7 Home Edition 64-bit operating system.

\subsection{Test system}

The test system in Fig. 2 is a base case system and consists of 8 synchronous generators, 8 buses, 7 loads and 22-transmission lines. A lumped synchronous generator is used in each bus as the equivalent of large cluster of power plants, and all electrical parameters have been scaled to cope with the studied demand scenario. It is a hypothetical simplification of a large $400 \mathrm{kV}$ transmission system. It has been divided into eight areas: Upper-Top, Top-Right, Topleft, Upper-Tail, Tail-Right, Lowest-Tail, Middle and Core + Tail. The synchronous generator G4 (a) represents the aggregation of a large number of classical generators and it is selected as a reference.

The system has a total generation of $100.736 \mathrm{GW}$ and a total load of $96.75 \mathrm{GW}$. The load flow is based on power interchange of about $15 \mathrm{GW}$ from the Top to Tail, particularly from Upper-Tail and Tail-Right and Core-Tail. Tail is a generation-rich area and Core-Tail is a load-rich area. Dynamic models for governor and automatic voltage controller (AVR) are included into the test system.

General steam turbine model is used as the governor for all synchronous power plants and a version in IEEE Type I excitation system [22] is used as AVR. For the system demand of $100 \mathrm{GW}$, the equivalent system inertia of 7.2 


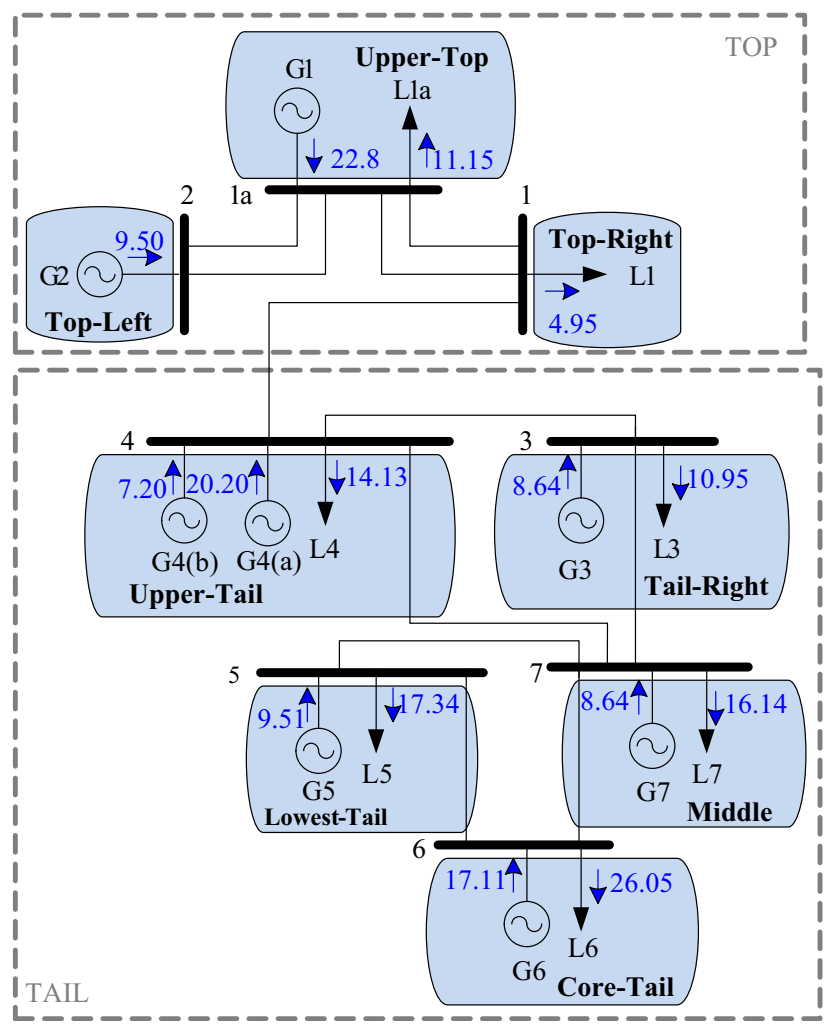

Fig. 2 Test system

MWs/MVA is assumed for the synchronous power plants without wind. The demand is considered to be $100 \%$ dynamic with a time constant of $0.10 \mathrm{~s}$ and the frequency dependence of active power is included.

\subsection{Frequency response assumptions}

The operational-control criteria used for system frequency analysis is a specific criteria which is mainly a personal version of the GB Security and Quality of Supply Standards (GB SQSS) [17]. The following assumptions are used: (1) the level of infrequency loss of power infeed is set up to $1800 \mathrm{GW}$, and frequency response must avoid a deviation of the system frequency outside statutory limit: which range $49.8-50.2 \mathrm{~Hz}$ for more than 5 cycles, (2) the level of normal loss of power infeed is set up to $1.35 \mathrm{GW}$ for frequency response to avoid a deviation in the system frequency by more than $0.20 \mathrm{~Hz}$, (3) the system frequency can rise to $52.0 \mathrm{~Hz}$ or fall to $47.0 \mathrm{~Hz}$ in exceptional circumstances. If system frequency is over $52.0 \mathrm{~Hz}$, overfrequency relays will trip generators, (4) frequency control devices (or a speed governor) are set up to operate with an overall speed Droop of 4\% (GB SQSS establishes between $3 \%$ and 5\%). In this paper, UFLS is set to start at $49.8 \mathrm{~Hz}$ and the plan consists of six load shedding steps of unequal size with the total amount of load shedding of $0.25 \mathrm{p} . \mathrm{u}$

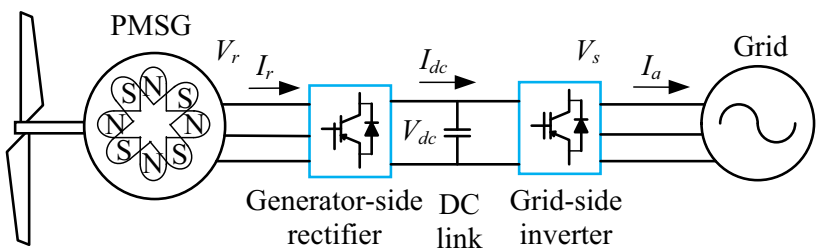

Fig. 3 General structure of VSWT with PMSG

[23]. A delay for each load shedding step is $0.1 \mathrm{~s}$ (5 cycles).

\subsection{Wind turbine model}

Figure 3 depicts the general structure of a variablespeed wind turbine (VSWT) with a direct-drive PMSG and Fig. 4 [23] shows the wind turbine model created using DSL.

The models for a back-to-back converter whose details of each model are taken $[24,25]$. The parameters for these models are escalated to simulate an equivalent $5 \mathrm{MW}$ wind turbine.

\subsection{Results and discussion}

The impact of an emulated inertia is being quantitatively analyzed through time-domain simulations. The test system is a multi-machine system, as consequence, this paper uses the concept of frequency of inertia centre $f_{\mathrm{c}}$ to analyse the changes in system frequency. The loss of power infeed is used as system frequency disturbance, and it consists of tripping at $t=1.00 \mathrm{~s}$ of one generating unit connected to Upper-Tail area at 1s (generator G4(b) in Fig. 3). The case base consists of synchronous generators (without wind) which feed system demand. This paper assumes four generators providing a governor frequency response and three conventional generators (G2, G5, and G7) will be operated without active governors (e.g., nuclear power stations) or at maximum power (e.g., valves wide open).

Several levels of loss of power infeed from $0.3-3.2 \mathrm{GW}$ are simulated and ROCOF is plotted in Fig. 5. The ROCOF and the minimum frequency increase as the level of loss of power infeed.

This paper uses an exceptional loss increase of power infeed to trigger a substantial frequency excursion in the test system. This system frequency disturbance activates the UFLS. This exceptional loss increase deviates system frequency more than $741 \mathrm{MHz}$ and persists for more than 5 cycles (see Fig. 6 and Case I Fig. 7). Several UFLS schemes on the demand side of Tail area are tested, whose loads are L4, L5, L6 and L7 (see Fig. 2). The results of system frequency and ROCOF are shown in Fig. 7 (load shedding for Case I: $0 \mathrm{GW}$, Case II: $2.8260 \mathrm{GW}$, Case III: 


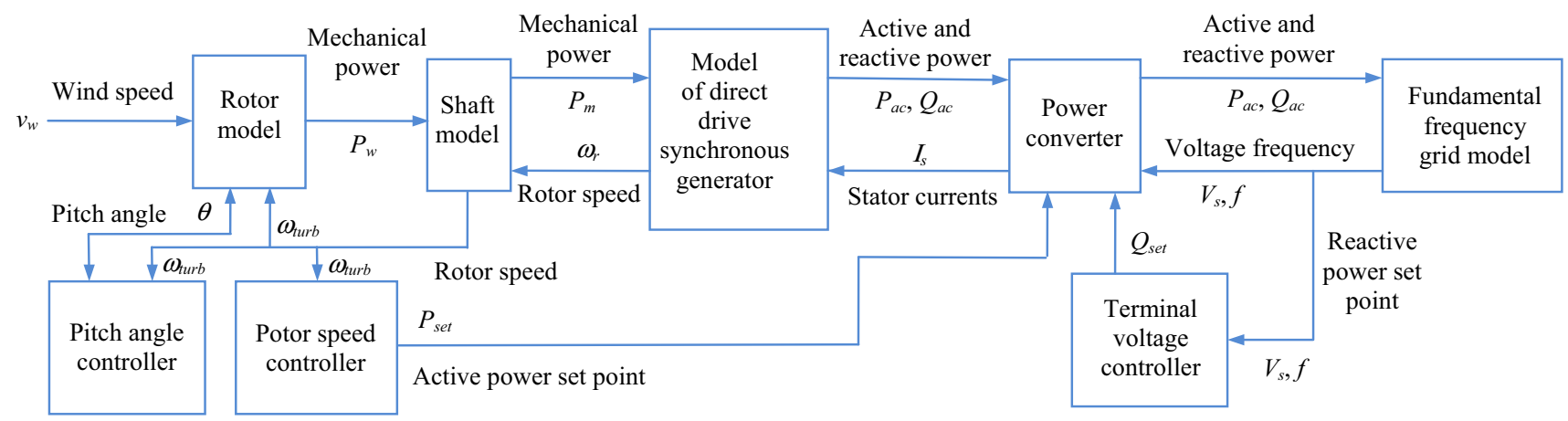

Fig. 4 Wind turbines model created using DSL

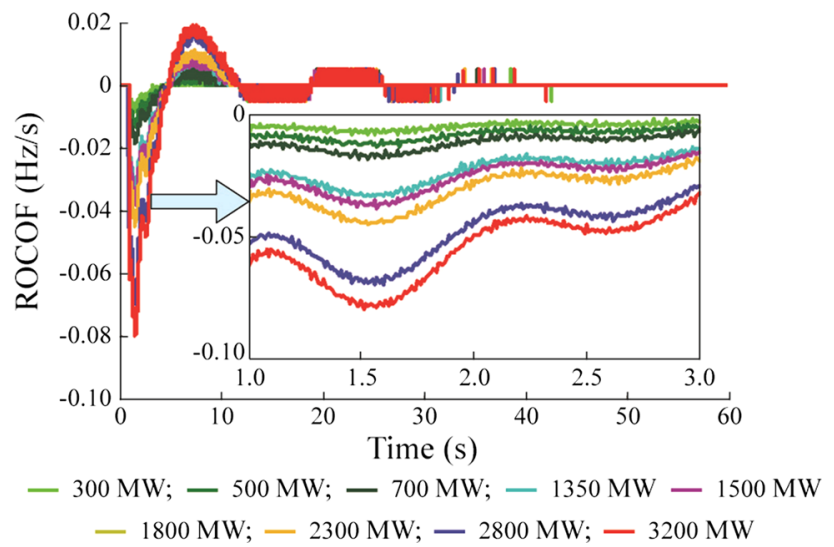

Fig. 5 ROCOF for several levels of loss of power infeed

6.2940 GW, Case IV: $5.7520 \mathrm{GW}$, and Case V: 7.3660 GW).

A cluster of wind farms is connected to bus 3 on the Tail-Right area and is generating $30 \mathrm{GW}$, and the combined (generator plus wind turbine) physical inertia of the equivalent wind farm is $H_{W F}=3.75 \mathrm{~s}$, which defines the total kinetic energy stored on the rotational components of the WTGs in steady-state condition. Benefits of the integration of this wind farm include the reduction of power flows between Top and Tail areas but an increase of $164 \mathrm{MHz}$ in the minimum frequency during at exceptional loss of the power infeed without inertial controller. The control loop for releasing hidden inertia is enabled in the wind farm and the effect of changing the inertial $H_{\text {emu }}$ on system frequency and ROCOF considering different UFLS schemes is shown in Fig. 8.

The inertial control has a substantial impact on system performance. The short term impact is the delivery of extra power from WT with substantially reducing the ROCOF, providing time for the active governors to respond (see Fig. 8). Increasing the capability of WT to release hidden inertia (increasing $H_{\text {emu }}$ ) helps to delay the

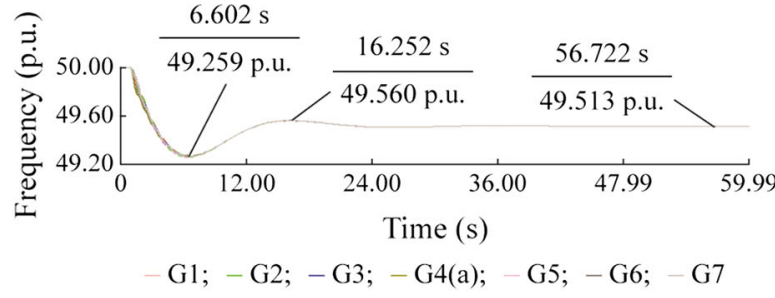

(a) Frequency

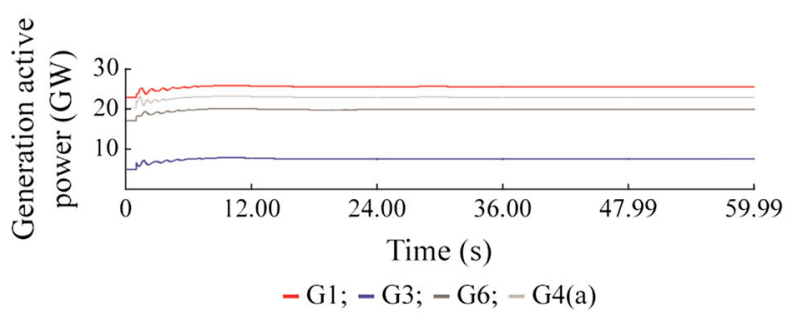

(b) Generation active power with frequnecy response

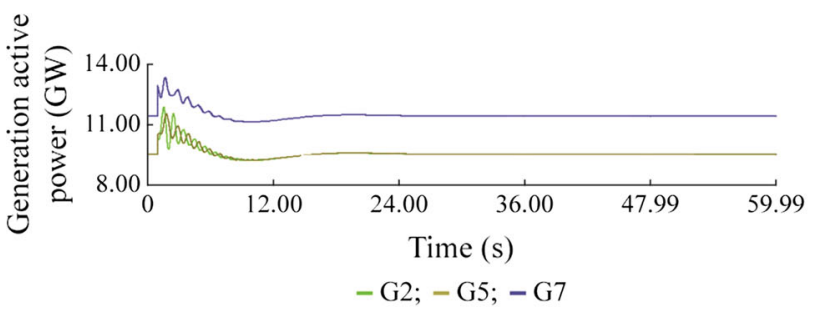

(c) Generation active power in $\mathrm{GW}$ without frequnecy response

Fig. 6 Frequency response to an exceptional loss of generation infeed

UFLS. However, the frequency response provided by emulated inertia cannot completely avoid UFLS. Decreasing the amount of emulated inertia reduces not only the recovery effect but also frequency support provided by wind farms. Results demonstrate UFLS helps to reduce the negative recovery effect caused by emulated inertia and increase security level during the extreme loss of power infeed. 

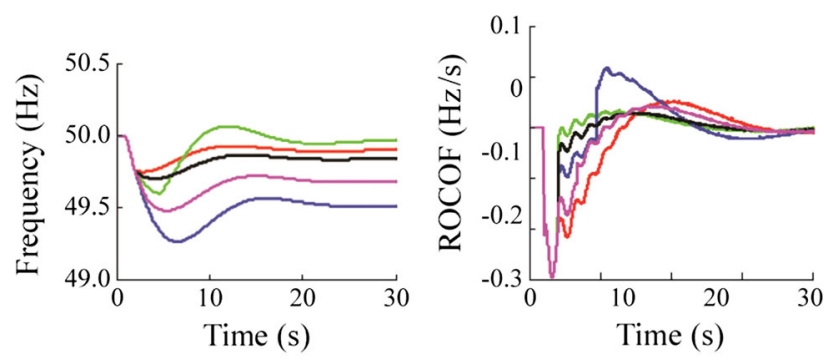

- I ; - II ; - III - IV $-\mathrm{V}$

Fig. 7 Frequency and ROCOF for different UFLS schemes
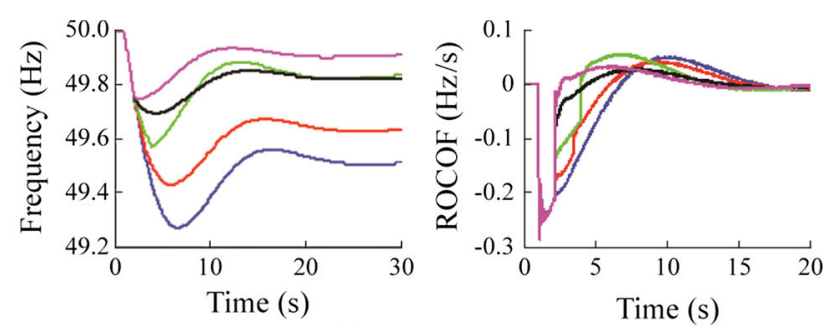

(a) $H_{e m u}=0.1 \mathrm{~s}$
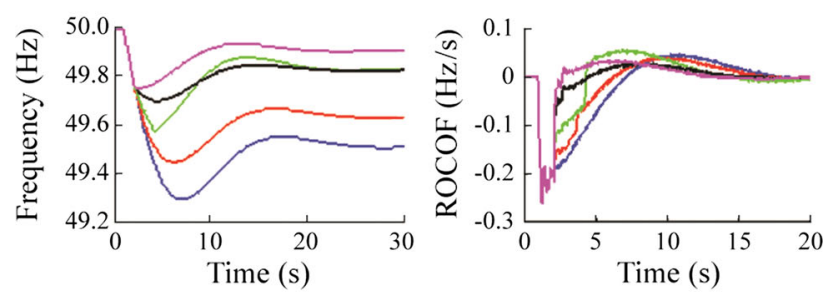

(b) $H_{e m u}=1.0 \mathrm{~s}$
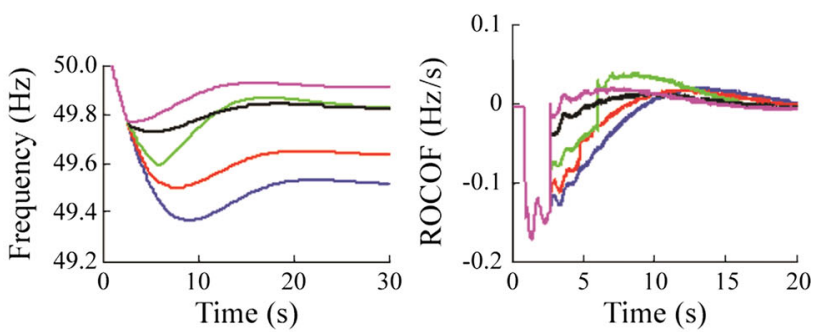

(c) $H_{\text {emu }}=5.0 \mathrm{~s}$
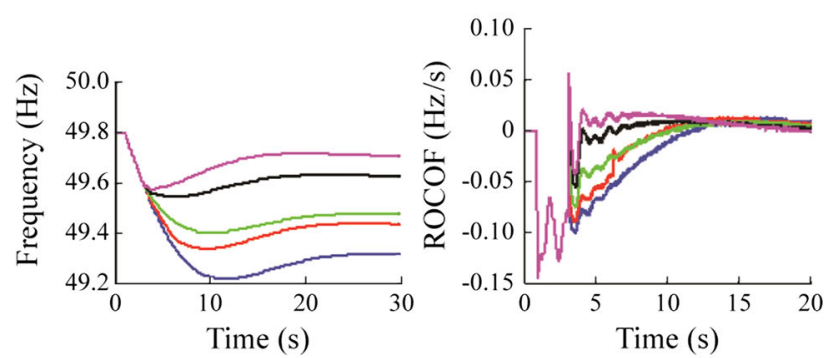

(d) $H_{e m u}=10.0 \mathrm{~s}$

$$
\text { - I ; - II ; - III - - IV - - V }
$$

Fig. 8 Frequency and ROCOF for different UFLS schemes with different $H_{\text {emu }}$

\section{Conclusions}

This paper presents the potential impact of emulated inertia from wind turbines on the under-frequency protection schemes during the recovery period after system frequency disturbances happen. The substantial impact of emulated inertia is on system inertial response: (1) the extra power delivered from WT can substantially reduce the ROCOF, (2) it provides time for the active governors to respond, but a coordination between the controllers is desirable (3) increasing synthetic inertia helps to delay the UFLS, (4) synthetic inertia cannot completely avoid UFLS, (5) UFLS helps to reduce the negative recovery effect caused by synthetic inertia. The main contribution of this paper is to demonstrate the recovery period of under-frequency transient in future power systems that integrate synthetic inertia capability and completely avoid worse scenarios in terms of UFLS.

Open Access This article is distributed under the terms of the Creative Commons Attribution 4.0 International License (http:// creativecommons.org/licenses/by/4.0/), which permits unrestricted use, distribution, and reproduction in any medium, provided you give appropriate credit to the original author(s) and the source, provide a link to the Creative Commons license, and indicate if changes were made.

\section{References}

[1] Gonzalez-Longatt FM (2014) Frequency control and inertial response schemes for the future power networks. In: Hossain J, Mahmud A (eds) Large scale renewable power generation. Springer, Singapore, pp 193-231

[2] Gonzalez-Longatt FM (2012) Effects of the synthetic inertia from wind power on the total system inertia: simulation study. In: Proceedings of the 2nd international symposium on environment friendly energies and applications (EFEA'12), Newcastle upon Tyne, UK, 25-27 Jun 2012, pp 389-395

[3] Gonzalez-Longatt FM (2012) Impact of synthetic inertia from wind power on the protection/control schemes of future power systems: simulation study. In: Proceedings of the 11th international conference on developments in power systems protection (DPSP '12), Birmingham, UK, 23-26 Apr 2012, 6 pp

[4] Ekamayake JB, Jenkins N, Strbac G (2008) Frequency response from wind turbines. Wind Eng 32(6):537-586

[5] Ekanayake J, Jenkins N (2004) Comparison of the response of doubly fed and fixed-speed induction generator wind turbines to changes in network frequency. IEEE Trans Energy Convers 19(4):800-802

[6] Erlich I, Wilch M (2010) Primary frequency control by wind turbines. In: Proceedings of the 2010 IEEE power and energy society general meeting, Minneapolis, MN, USA, 25-29 Jul 2010, 8 pp

[7] Erlich I, Winter W, Dittrich A (2006) Advanced grid requirements for the integration of wind turbines into the German transmission system. In: Proceedings of the 2006 IEEE power engineering society general meeting, Montreal, Canada, 18-22 Jun 2006, 7 pp 
[8] Lalor G, Mullane A, O’Malley M (2005) Frequency control and wind turbine technologies. IEEE Trans Power Syst 20(4):1905-1913

[9] Miller N, Clark K, Walling R (2009) WindINERTIA: controlled inertial response from GE wind turbine generators. In: Proceedings of the 45th annual Minnesota power systems conference, Minneapolis, MN, USA, 3-5 Nov 2009

[10] Miller NW, Clark K, Shao M (2011) Frequency responsive wind plant controls: impacts on grid performance. In: Proceedings of the 2011 IEEE power and energy society general meeting, San Diego, CA, USA, 24-29 Jul 2011, 8 pp

[11] Morren J, de Haan SWH, Kling WL et al (2006) Wind turbines emulating inertia and supporting primary frequency control. IEEE Trans Power Syst 21(1):433-434

[12] Ruttledge L, Flynn D (2011) System-wide inertial response from fixed speed and variable speed wind turbines. In: Proceedings of the 2011 IEEE power and energy society general meeting, San Diego, CA, USA, 24-29 Jul 2011, 7 pp

[13] Seman S, Sakki R (2011) Inertial response-generators and the power electronics. ABB Group, Zurich

[14] Singh M, Vyas M, Santoso S (2010) Using generic wind turbine models to compare inertial response of wind turbine technologies. In: Proceedings of the 2010 IEEE power and energy society general meeting, Minneapolis, MN, USA, 25-29 Jul 2010, 7 pp

[15] Teninge A, Jecu C, Roye D et al (2009) Contribution to frequency control through wind turbine inertial energy storage. IET Renew Power Gener 3(3):358-370

[16] Grid code. National Grid, London, UK, 2010

[17] Security and quality of supply standard (SQSS). National Grid, London, UK, 2009

[18] Gonzalez-Longatt FM, Luis Rueda J, Charalambous CA et al (2014) Estimation of equivalent model for cluster of induction generator based on PMU measurements. In: Gonzalez-Longatt FM, Luis Rueda J (eds) Power factory applications for power system analysis. Springer International Publishing, Heidelberg, pp 473-489

[19] Wall P, Gonzalez-Longatt FM, Terzija V (2012) Estimation of generator inertia available during a disturbance. In: Proceedings of the 2012 IEEE power and energy society general meeting, San Diego, CA, USA, 22-26 Jul 2012, 8 pp

[20] WindINERTIA control fact sheet. General Electric Company, Fairfield, CT, USA, 2009

[21] DIgSILENT power factory, v14.0.524.2. DIgSILENT, Gomaringen, Germany, 2011
[22] IEEE Std 421.5-1992 IEEE recommended practice for excitation system models for power system stability studies. 1992

[23] Gonzalez-Longatt FM (2006) Dynamical model of variable speed WECS: attend of simplification. In: Proceedings of the 5th international workshop on large scale integration of wind power and transmission networks for offshore wind farms, Glasgow, UK, 26-28 Oct 2006, 8 pp

[24] González-Longatt FM, Wall P, Terzija V (2011) A simplified model for dynamic behavior of permanent magnet synchronous generator for direct drive wind turbines. In: Proceedings of the 2011 IEEE Trondheim PowerTech conference, Trondheim, Norway, 19-23 Jun 2011, 7 pp

[25] Achilles S, Pöller M (2015) Direct drive synchronous machine models for stability assessment of wind farms. In: Proceedings of the 4th international workshop on large scale testing (LT'15), Austin, TX, USA, 31 Jan-4 Feb 2015, 9 pp

Francisco Manuel GONZALEZ-LONGATT is currently a Lecturer in Electrical Power System at Electrical Power System in School of Electronic, Electrical and Systems Engineering at Loughborough University. His academic qualifications include first Class Electrical Engineering of Instituto Universitario Politécnico de la Fuerza Armada Nacional, Venezuela (1994), Master of Business Administration (Honors) of Universidad Bicentenaria de Aragua, Venezuela (1999) and PhD in Electrical Power Engineering from the Universidad Central de Venezuela (2008). He is former associate professor (1995-2009) and Chair (1999-2001) of the Department of Electrical Engineering of Universidad Nacional Politécnico de la Fuerza Armada Nacional, Venezuela (1995-2009). He is a former academic staff of Department of Aerospace, Electrical and Electronic Engineering at University of Coventry where he started as Lecturer in Electrical Engineering in 2012 and promoted to Senior Lecturer in Electrical Engineering in 2013. He was formerly with the School of Electrical and Electronic Engineering, The University of Manchester as Postdoctoral Research Associate (2009-2011). He is Vice-President of Venezuelan Wind Energy Association, Senior Member of the IEEE, member of The Institution of Engineering and TechnologyThe IET (UK) and member of International Council on Large Electric Systems-CIGRE. His research interest includes innovative (operation/control) schemes to optimize the performance of future energy systems. 